\title{
Subpollen particles: Carriers of allergenic proteins and oxidases
}

\author{
Attila Bacsi, PhDa, ${ }^{*}$, Barun K. Choudhury, PhD $^{b}$, Nilesh Dharajiya, MD $^{\mathrm{b}}$, Sanjiv Sur, MD $^{\mathrm{b}}$, \\ and Istvan Boldogh, $\mathrm{PhD}^{\mathrm{a}}$ \\ aDepartment of Microbiology and Immunology, University of Texas Medical Branch, Galveston, \\ Tex.

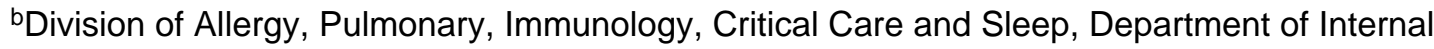 \\ Medicine, University of Texas Medical Branch, Galveston, Tex.
}

\section{Abstract}

Background-Pollen is known to induce allergic asthma in atopic individuals, although only a few inhaled pollen grains penetrate into the lower respiratory tract.

Objective-We sought to provide evidence that subpollen particles (SPPs) of respirable size, possessing both antigenic and redox properties, are released from weed pollen grains and to test their role in allergic airway inflammation.

Methods-The release of SPPs was analyzed by means of microscopic imaging and flow cytometry. The redox properties of SPPs and the SPP-mediated oxidative effect on epithelial cells were determined by using redox-sensitive probes and specific inhibitors. Western blotting and amino acid sequence analysis were used to examine the protein components of the SPP. The allergenic properties of the SPP were determined in a murine model of experimental asthma.

Results-Ragweed pollen grains released 0.5 to $4.5 \mu \mathrm{m}$ of SPPs on hydration. These contained Amb a 1, along with other allergenic proteins of ragweed pollen, and possessed nicotinamide adenine dinucleotide (reduced) or nicotinamide adenine dinucleotide phosphate (reduced) $[\mathrm{NAD}(\mathrm{P}) \mathrm{H}]$ oxidase activity. The SPPs significantly increased the levels of reactive oxygen species (ROS) in cultured cells and induced allergic airway inflammation in the experimental animals. Pretreatment of the SPPs with NAD(P)H oxidase inhibitors attenuated their capacity to increase ROS levels in the airway epithelial cells and subsequent airway inflammation.

Conclusions-The allergenic potency of SPPs released from ragweed pollen grains is mediated in tandem by ROS generated by intrinsic NAD(P)H oxidases and antigenic proteins.

Clinical implications-Severe clinical symptoms associated with seasonal asthma might be explained by immune responses to inhaled SPPs carrying allergenic proteins and ROS-producing $\mathrm{NAD}(\mathrm{P}) \mathrm{H}$ oxidases.

\section{Keywords}

Subpollen particles; oxidative stress; inflammation

Pollen allergens are a major cause of allergic reactions in the skin, eyes, and upper and lower respiratory tracts during the flowering season. $1^{-} 4$ How pollen-carried allergens

\footnotetext{
(C) 2006 American Academy of Allergy, Asthma and Immunology

Reprint requests: Istvan Boldogh, DM\&B, PhD, Department of Microbiology and Immunology, University of Texas Medical Branch, 3.170 Medical Research Building, 301 University Blvd, Galveston, TX 77555. sboldogh@utmb.edu..

* Dr Bacsi is currently affiliated with the Institute of Immunology, University of Debrecen, Debrecen, Hungary.

Disclosure of potential conflict of interest: The authors have declared that they have no conflict of interest.
} 
contribute to the development of inflammation in the lower airways of the lungs has remained a puzzle because only a small percentage of pollen grains deposit in the peripheral airways. It has been shown that hydration in rainwater, high humidity conditions, and moisture can cause the expulsion of pollen grains from grasses and trees, leading to the release of allergen-containing micronic and submicronic particles $(0.12-5 \mu \mathrm{m}) .5^{-} 8$ These findings correlate with previous reports showing that significant allergen exposure can occur in the absence of identifiable pollen grains in the air.9 Similarly, allergen levels are increased in the environment in the flowering season, especially after heavy rainfall, which correlates with the increased frequency of hospital admissions of atopic individuals.10

The pollen of short ragweed (Ambrosia artemisiifolia) is one of the most abundant aeroallergens causing severe seasonal allergic symptoms in the United States and Canada. This wind-pollinated flowering plant produces large amounts of pollen. Exposure to ragweed pollen antigens has been shown to elicit allergic responses.11 The molecular characterization of ragweed pollen revealed Amb a 1 to be the predominant allergen.12 More then $90 \%$ of ragweed-sensitive subjects have antibodies against Amb a 1.12 However, there is a poor correlation between pollen counts and the abundance of airborne allergens, suggesting that allergen exposure might occur in the absence of pollen grains.9.13 Indeed, it has been proposed that submicronic particles that easily penetrate the lower airways represent the major allergen source and are the cause of severe asthma associated with the pollen season.3 $14^{-1} 16$ In support, ragweed allergens have been identified in the form of fine particles with sizes ranging from 0.2 to $5.25 \mu \mathrm{m}$ from outdoor air samples analyzed by a nonviable cascade impactor.13 Yet the generation of subpollen particles (SPPs) has not been observed for ragweed or other weed species.

We recently reported that, in addition to their allergenic proteins, ragweed pollen grains contain intrinsic $\mathrm{NAD}(\mathrm{P}) \mathrm{H}$ oxidases, which generate oxidative stress ("signal 1") in the airway epithelium within minutes of exposure. This process is required for antigen ("signal 2")-mediated robust inflammation in the lower airways.17,18 Because of their size, the relevance of ragweed pollen grains to lung inflammation has remained unclear. Here we demonstrate that on hydration, the viable ragweed pollen produced SPPs through biochemically active processes. The SPPs retained pollen grains' NAD(P)H oxidases, Amb a 1, and other antigenic components and induced robust inflammation in the lower airways. These findings might explain the increased allergen levels in the absence of identifiable pollen grains and the severe asthma symptoms associated with the pollen season.

\section{METHODS}

\section{Cell cultures}

A549 bronchial epithelial cells were obtained from the American Type Cell Collection and cultured in Ham's F- 12 medium at $37^{\circ} \mathrm{C}$ in a humidified atmosphere with $5 \% \mathrm{CO}_{2}$. Primary normal human bronchial epithelial (NHBE) cells (Cambrex Bio Science, Walkersville, Md) were cultured in BEGM BulletKit medium supplied by the manufacturer. We also conducted experiments using NHBE cells grown in an air-liquid interface, as previously described.18

\section{Animals, sensitization, and challenge}

Animal experiments were performed according to the National Institutes of Health "Guide for the care and use of experimental animals" and approved by the University of Texas Medical Branch Animal Care and Use Committee (no. 9708038-05). Six- to 8-week-old female BALB/c mice purchased from Harlan Sprague-Dawley (San Diego, Calif) were used for these studies. The mice were sensitized intraperitoneally on days 0 and 4 with ragweed pollen extract (RWE; Greer Laboratories, Lenoir, NC) at a dose of $150 \mu \mathrm{g}$ per mouse, which 
was mixed with alum, as previously described.18 On day 11, parallel groups of mice ( $\mathrm{n}=$ 6-9) were challenged intranasally with SPPs $(25 \mu \mathrm{g})$, SPPs $(25 \mu \mathrm{g})$ plus quinacrine (QA; 5 mM; Sigma-Aldrich, St Louis, Mo), Amb a 1 ( $25 \mu \mathrm{g}$, Greer Laboratories), or Amb a 1 (25 $\mu \mathrm{g})$ plus QA $(5 \mathrm{mM})$.

\section{Enrichment of SPPs}

Freshly collected A artemisiifolia and redroot pigweed (Amaranthus retroflexus) pollen grains were hydrated in rainwater for 90 minutes, and the intact grains were removed from the suspension by means of low-speed centrifugation ( 5 minutes at $1600 g$ ). The SPPs were collected from the pollen grain-free supernatants by means of centrifugation at $9000 \mathrm{~g}$ for 15 minutes. Pellets containing SPPs were resuspended in Dulbecco's PBS.

\section{Determination of SPP size}

A Becton Dickinson flow cytometer (Franklin Lakes, NJ) and size standards were used to determine the size of the SPP. The flow cytometry calibration kit contained 1.1-, 4-, 10-, 15-, 20-, and 30- $\mu \mathrm{m}$ standards (Molecular Probes, Eugene, Ore). The data were collected with respect to forward-scatter and side-scatter parameters. 19

\section{Western blot analysis}

Protein lysates were separated on 10\% SDS-polyacrylamide gels and blotted onto Hybond membranes (Amersham Biosciences, Piscataway, NJ). The blocked membranes were incubated with primary antibody (anti-Amb a 1; Alpha Diagnostic, San Antonio, Tex) at a 1:1500 dilution in Tris-buffered saline with Tween 20 plus 5\% milk. The binding of the primary antibody was detected with horseradish peroxidase-conjugated secondary antibodies (Amersham). Subsequently, membranes were washed and incubated in ECL Western blotting detection reagent (Amersham). In parallel experiments separated proteins in the gel were visualized by staining with Coomassie blue.

\section{Sequence analysis}

After electrophoretic separation and blotting onto polyvinylidene difluoride membranes, the resulting polypeptides were subjected to $(\mathrm{N})$-terminal amino-acid microsequencing. Sequencing of 15 amino acids at the N-terminal end was undertaken to identify the 38-kd protein in SPPs. This work was performed by the Protein Chemistry Laboratory of the University of Texas Medical Branch by using a 494/HT Procise sequencing system controlled by Procise control software and SeqPro data analysis software (Applied Biosystems, Foster City, Calif).

\section{Measurement of intracellular reactive oxygen species}

NHBE or A549 cells grown to $70 \%$ confluence were loaded with $50 \mu \mathrm{M} 2^{\prime}-7^{\prime}$-dihydrodichlorofluorescein diacetate $\left(\mathrm{H}_{2}\right.$ DCF-DA; Molecular Probes) at $37^{\circ} \mathrm{C}$ for 15 minutes. 18 After removing any excess probe, the cells were exposed to SPPs for 30 minutes and washed twice with PBS. A change in dichlorofluorescein (DCF)-mediated fluorescence intensity was assessed in an FLx800 micro-plate reader (Bio-Tek Instruments, Winooski, Vt) at 488$\mathrm{nm}$ excitation and 530-nm emission. Nitroblue tetrazolium (NBT; $2 \mathrm{mM}$ ) was mixed with SPPs or with SPPs treated by heat $\left(10\right.$ minutes at $\left.72^{\circ} \mathrm{C}\right)$, diphenyleneiodonium (DPI; 100 $\mu \mathrm{M}$; Sigma-Aldrich), QA (5 mM; Sigma-Aldrich), catalase (400 U/mL; Sigma-Aldrich), or superoxide dismutase (50 U/mL; Calbiochem, San Diego, Calif). In selected experiments Amb a 1 or glucose oxidase ( $75 \mathrm{U} / \mathrm{mL}$; Roche, Indianapolis, Ind) and $\beta$-D-glucose $(1 \mu \mathrm{M})$ were mixed with NBT. The mixtures were then incubated for 15 minutes at $37^{\circ} \mathrm{C}$. Waterinsoluble formazan particles were collected by means of centrifugation, and the formazan was dissolved in methanol.17, 18 The optical density was determined at $530 \mathrm{~nm}$ on a 
spectrophotometer (DU 530; Beckman Instruments, Fullerton, Calif). The redox properties of the pollen grains and SPPs were measured in a thermo-controlled microscopic chamber. DCF fluorescence was visualized with a Nikon Eclipse TE 200 ultraviolet microscope. Images were taken with a Photometrix CoolSNAP Fx digital camera with the aid of Metamorph software (Version 5.09r; Universal Imaging, Downingtown, Pa).

\section{In situ gel NBT assay}

SPPs were treated with Triton X-100 (Sigma-Aldrich), and $50 \mu \mathrm{g}$ per lane was electrophoresed on a $6 \%$ nondenaturing polyacrylamide gel at $4^{\circ} \mathrm{C}$. The gel was immersed in NBT solution $(2 \mathrm{mM})$ containing $1 \mathrm{mM}$ NAD(P)H18 and photographed after it had been color developed.17, 18

\section{Evaluation of airway inflammation}

Cellular recruitment into the airway lumen was assessed by means of analysis of the bronchoalveolar lavage (BAL) fluid 72 hours after challenge.18 BAL of the lungs was performed twice with $0.75 \mathrm{~mL}$ of sterile PBS (pH 7.3). Total cell counts in the BAL fluid were determined, and differential cell counts were performed on cytocentrifuge preparations (Cytospin 3; Thermo Shandon, Pittsburgh, Pa) stained with Wright-Giemsa. The formalinfixed lungs were embedded in paraffin, sectioned at a thickness of $4 \mu \mathrm{m}$, and stained with hematoxylin and eosin or periodic acid-Schiff. The inflammatory and mucus-producing goblet cells were documented with a Photometrix CoolSNAP Fx camera mounted on a NIKON Eclipse TE 200 microscope interfaced with Metamorph software.

\section{Statistics}

Data from the different treatment groups were analyzed by means of ANOVA, followed by Bonferroni post hoc analyses for least-significant differences. Differences were considered to be statistically significant at a $P$ value of less than .05 .

\section{RESULTS}

\section{Oxidative stress augments release of SPPs}

On hydration in rainwater or $0.05 \mathrm{M} \mathrm{Na}_{2} \mathrm{CO}_{3}$ solution, approximately $35 \%$ of the freshly collected ragweed pollen grains released SPPs, leaving only an empty shell behind, as observed by means of phase-contrast microscopy (Fig 1,A). The release of SPPs was observed starting at 3 to 5 minutes after hydration and continuing up to 60 minutes, and the emission of SPPs occurred through a single pore. Approximately $0.1 \%$ to $0.5 \%$ of the commercially purchased pollen grains released SPPs. Microscopic size determinations and flow cytometric analysis of the SPPs showed that the size of the released particles varied between 0.5 and $4.5 \mu \mathrm{m}$ in diameter (Fig $1, B$ ). Similar results were obtained with redroot pigweed, for which $45 \%$ of the pollen grains released SPPs with comparable size (data not shown).

We previously showed that ragweed and 39 other extracts of pollen and pollen grains possessed $\mathrm{NAD}(\mathrm{P}) \mathrm{H}$ oxidase activities.17,18 Therefore we sought to determine whether $\mathrm{NAD}(\mathrm{P}) \mathrm{H}$ oxidase-generated oxidative stress promotes the release of SPPs from pollen grains. First, we confirmed the redox activity of ragweed and redroot pigweed pollen grains by suspending them in NBT20 solution in the presence or absence of $\mathrm{NAD}(\mathrm{P}) \mathrm{H}$ oxidase substrates, NADPH $(100 \mu \mathrm{M})$, or nicotinamide adenine dinucleotide, reduced (NADH) (100 $\mu \mathrm{M}$ ). A deposit of formazan crystals was observed at the site of SPP release (Fig 2, A). To confirm these data, we conducted DCF assays.17 As shown in Fig 2, $B$ and $C$, pollen grains exhibited bright DCF fluorescence. Interestingly, $72 \%$ to $81 \%$ of the freshly collected pollen grains showed intense fluorescence, whereas 35\% (ragweed) and 40\% (pigweed) of the 
pollen grains released SPPs (Fig 2,D). These results are similar to the data obtained by using an NBT assay (data not shown). The addition of DPI $(10 \mu \mathrm{M})$ or QA $(25 \mu \mathrm{M}) 21$ significantly decreased the numbers of pollen grains releasing SPPs (Fig 2,E). The activation of plant $\mathrm{NAD}(\mathrm{P}) \mathrm{H}$ oxidases requires a cascade of events involving the mitogenactivated protein kinase (MAPK) pathway.22 The addition of SB-202190 $(20 \mu \mathrm{M})$, which is a MAPK inhibitor,23 decreased the SPP release, whereas the addition of SP-600125, which is a c-Jun $\mathrm{NH}(2)$-terminal kinase inhibitor,23 showed no effect on SPP release (Fig 2, E). Taken together, these findings suggest that in fresh pollen the activation of the MAPK pathway and oxidative stress generated by $\mathrm{NAD}(\mathrm{P}) \mathrm{H}$ oxidases contribute to SPP release.

\section{NAD(P)H oxidases are transmitted into SPPs}

Next we tested the possibility that the $\mathrm{NAD}(\mathrm{P}) \mathrm{H}$ oxidases of the pollen grains are also present in the SPPs. As shown in Fig 3, A, incubation of SPPs with $\mathrm{H}_{2}$ DCF-DA ( $1 \mu \mathrm{M}$ final concentration) resulted in the rapid formation of fluorescent DCF. To confirm these observations, we showed that a ragweed SPP suspension reduced NBT to formazan. Superoxide dismutase rapidly converted $\mathrm{O}_{2} \cdot{ }^{-}$into $\mathrm{H}_{2} \mathrm{O}_{2}$, which decreased formazan formation. Adding catalase to the reaction mixture had no effect on the formazan formation. The inactivation of the $\mathrm{NAD}(\mathrm{P}) \mathrm{H}$ oxidases by heat $\left(72^{\circ} \mathrm{C}\right.$ for 15 minutes) or the addition of DPI and QA21 significantly decreased the NBT-reducing activity of SPP (Fig 3, B). Purified Amb a 1 failed to reduce the NBT (Fig 3,B). Glucose oxidase, which primarily generates superoxide24 similar to $\mathrm{NAD}(\mathrm{P}) \mathrm{H}$ oxidases, 21 was used as a positive control. Furthermore, we fractionated the SPP proteins by using a nondenaturing polyacrylamide gel and performed in situ NBT assays. Well-defined protein bands possessing NBT-reducing activity were observed (Fig 3,C). Taken together, these data suggest that $\mathrm{NAD}(\mathrm{P}) \mathrm{H}$ oxidases present in the pollen grains are transmitted to the SPPs.

\section{Amb a 1 is present in SPPs}

To define the protein composition of ragweed SPPs, we performed denaturing PAGE analyses. Coomassie brilliant blue G250 staining showed that the proteins in the SPPs had a similar electrophoretic pattern to those found in commercial RWE (Fig 4, A). Western blot analysis revealed a 38-kd protein band corresponding to Amb a 1, the major antigenic component of ragweed pollen (Fig 4,B).12 RWE and purified Amb a 1 were used as positive controls (Fig $4, B$ ). Protein sequence analysis showed that 15 amino acids at the Nterminus of the 38-kd proteins in SPPs and RWE showed 100\% sequence homology with Amb a 1.

\section{SPPs increase intracellular reactive oxygen species levels in cultured cells}

Building on the observation that SPPs have redox activity, we sought to determine whether they increase the reactive oxygen species (ROS) levels in cultured epithelial (NHBE and A549) cells. NHBE cells were grown either submerged or in an air-liquid interphase.18 After loading the cells with $\mathrm{H}_{2}$ DCF-DA, SPPs $(20 \mu \mathrm{g} / \mathrm{mL})$ were added to the cultures. The SPPs rapidly increased the intracellular DCF fluorescence in the submerged and air-liquid interphase NHBE cells (Fig 5, A). Similar results were obtained with A549 cells (Fig 5, B). The increase in the intracellular ROS level was prevented by means of heat treatment of SPPs or pretreatment of the cells with N-acetyl-L-cysteine (Fig 5), which increases the antioxidant capacity of cells.25 Pretreatment of the SPP suspension with the NAD $(\mathrm{P}) \mathrm{H}$ oxidase inhibitors QA or DPI significantly decreased the intracellular oxidative stress levels in both NHBE and A549 cells (Fig 5). Pigweed SPPs induced ROS levels in A549 cells that were similar to those induced by ragweed SPPs (data not shown). Glucose oxidase (100 ng/ $\mathrm{mL}$ ) served as a positive control. 


\section{SPPs induce robust airway inflammation}

Previously, we showed that ragweed pollen grain extract or pollen grains robustly increased ROS levels in the lining cells of airways and the conjunctival epithelium.17,18 Not surprisingly, because of the $\mathrm{NAD}(\mathrm{P}) \mathrm{H}$ oxidase activity of SPPs, a rapid increase in ROS levels in the airway lining cells was observed after intratracheal challenge with the SPP suspension (data not shown). To determine the ability of SPPs to induce allergic inflammation, we used an experimental mouse model of asthma. Sensitized mice were challenged intranasally with either PBS, Amb a $1(25 \mu \mathrm{g})$, or SPP suspension $(25 \mu \mathrm{g})$. Using SDS-PAGE and densitometric analysis, we determined that SPPs $(25 \mu \mathrm{g})$ contained approximately $2.1 \mu \mathrm{g}$ of Amb a 1 (data not shown). SPP challenge of the sensitized mice induced robust inflammation, as determined by the number of eosinophils and total inflammatory cells in the BAL fluids and the peribronchial area, compared with Amb a 1 challenge (Fig 6). Adding the NAD(P)H oxidase inhibitor QA to the challenge materials significantly decreased the accumulation of eosinophils (Fig $6, A$ ) and the total number of inflammatory cells (Fig 6, B). The accumulation of eosinophils in the peribronchial area and the increase in the number of mucin-producing cells were visibly greater in the lung sections of SPP-challenged animals than in Amb a 1-challenged animals (Fig 6,C). The inhibition of $\mathrm{NAD}(\mathrm{P}) \mathrm{H}$ oxidase activity by QA decreased the ability of SPPs to induce goblet cell metaplasia in the airway epithelium (Fig 6, C). In nonsensitized mice neither SPP nor Amb a 1 induced lung inflammation (data not shown), similar to ragweed extract.18 Taken together, these findings suggest that SPPs are potent inducers of inflammation in the lower airways because of their antigenic content and $\mathrm{NAD}(\mathrm{P}) \mathrm{H}$ oxidase-generated oxidative stress.

\section{DISCUSSION}

We previously reported that pollen grain extracts of weeds, grasses, and trees contain intrinsic $\mathrm{NAD}(\mathrm{P}) \mathrm{H}$ oxidases, which generate oxidative stress in the lungs and conjunctival epithelium within minutes of exposure.17, 18 Oxidative stress generated by the $\mathrm{NAD}(\mathrm{P}) \mathrm{H}$ oxidases of RWE significantly augmented the metaplasia of mucin-producing cells and the accumulation of inflammatory cells in the BAL and peribronchial areas.18 However, because of the size of ragweed pollen grains, their role in inflammation of the lower airway has not been fully understood. Here we present evidence that freshly collected ragweed and pigweed pollen grains release SPPs of respirable size after hydration. Active biochemical processes are required for the formation of SPPs. This theory is supported by several observations.

First, only fresh pollens release SPPs. Illustrating the importance of pollen viability in SPP formation, grass pollen grains were observed to be ruptured while enclosed within the moistened anthers. 8

Second, $\mathrm{NAD}(\mathrm{P}) \mathrm{H}$ oxidases are generally present in an inactive form and are activated through a cascade of events involving activation of the MAPK pathway, protein-protein interactions, and activation of Rac/Rop guanosine triphosphate-binding proteins. 26 Therefore our findings that the MAPK inhibitor SB-202190 decreased the numbers of pollen grains releasing SPPs were not surprising.

Third, inactivation by heat or inhibition by DPI and QA of NAD(P)H oxidase-dependent free radical generation significantly decreased SPP release. This was consistent with the concept of $\mathrm{ROS}\left(\mathrm{H}_{2} \mathrm{O}_{2}\right.$ and $\left.\cdot \mathrm{OH}\right)$-mediated damage to cell wall polysaccharides, allowing exoglucanase and endoglucanase actions, before cell elongation or cell division.27

Fourth, a morphologic examination showed that pollen grains releasing SPPs resembled the apoptotic-like bodies often seen in mammalian 28 and plant 29 cells. Moreover, the inhibition 
of SPP release by a caspase inhibitor cocktail was further evidence for their active formation (presently under detailed investigation). Thus the SPPs released under laboratory conditions could be similar to the allergen-containing particles that are released from pollen grains during rainfall or moisture conditions. 8

Most importantly, we showed that SPPs possess NAD(P)H oxidase activity and contain major proteins of pollen grains, including Amb a 1. An initial characterization (DCF, NBT, and in situ gel assays) showed that the $\mathrm{NAD}(\mathrm{P}) \mathrm{H}$ oxidases in $\mathrm{SPP}$ produce $\mathrm{O}_{2} \cdot{ }^{-}$by transferring electrons from NADPH or NADH to molecular oxygen.30 In the presence of nonenzymatic (metal ions) and enzymatic processes, $\mathrm{O}_{2}{ }^{-}$is converted into more reactive species 31 and causes a robust increase in cellular ROS levels in cultured airway epithelial cells. In addition, Western blot analysis of ragweed SPP lysates showed the presence of Amb a 1, along with other proteins, in RWE. These data support a recent publication by Grote et al, 15 who showed that birch pollen ruptured in rainwater and released Bet v 1containing particles.

Our data show that the SPPs of ragweed have the ability to induce robust allergic lung inflammation, which is consistent with the presence of $\mathrm{Amb}$ a 1 and $\mathrm{NAD}(\mathrm{P}) \mathrm{H}$ oxidase activity. $\mathrm{NAD}(\mathrm{P}) \mathrm{H}$ oxidase-generated $\mathrm{O}_{2}{ }^{-}$is converted into more-reactive species, 31 which serve as the "signal 1,"18 and are consistent with our data showing a much higher level of airway inflammation induced by SPPs (containing $2.1 \mu \mathrm{g}$ Amb a 1) than by Amb a 1 (25 $\mu \mathrm{g})$. Reactive species, either directly or through the formation of lipid-peroxidation products, such as acrolein, 4-hydroxy-2-nonenal, and $\mathrm{F}(2)$-isoprostanes, play a role in enhancing inflammation through the activation of various stress kinases (eg, extracellular signalregulated kinase, c-Jun $\mathrm{NH}(2)$-terminal kinase, MAPK, and p38) and redox-sensitive transcription factors (eg, nuclear factor $\mathrm{\kappa B}$ and activator protein-1 [AP-1]), leading to increased inflammatory cytokine production.32,33

In conclusion, to our knowledge, this is the first report showing a group of allergenic proteins and $\mathrm{NAD}(\mathrm{P}) \mathrm{H}$ oxidase activity in SPPs of respirable size produced by weeds. The $\mathrm{NAD}(\mathrm{P}) \mathrm{H}$ oxidase-generated oxidative stress and the allergenic proteins of the SPPs act in concert to orchestrate the development of robust allergic inflammation. Along with our previous observation that pollen grain extracts from weeds, trees, and grasses contain $\mathrm{NAD}(\mathrm{P}) \mathrm{H}$ oxidases, this study provides insight into the role of SPPs in epidemics of seasonal asthma. Our data also suggest that inhibitors of SPP-associated oxidases or scavengers of oxidant species might be useful tools to prevent or decrease the localized oxidative insults and inflammation.

\section{Acknowledgments}

We thank Dr N. Garg (Department of Microbiology and Immunology, University of Texas Medical Branch) and International Science Editing, Ireland, for critically reading and editing the manuscript.

Supported by the National Institutes of Health (RO1-HL07163-01; Sur, Boldogh), National Institute of Heart Lung and Blood Proteomics Initiatives (NO1-HV28184), the National Institute of Allergic and Infectious Diseases (PO1AI062885-01; Boldogh, Sur), and the National Institute of Environmental Health and Sciences (ES06676).

\section{Abbreviations used}

$\begin{array}{ll}\text { BAL } & \text { Bronchoalveolar lavage } \\ \text { DCF } & \text { Dichlorofluorescein } \\ \text { DPI } & \text { Diphenyleneiodonium }\end{array}$




$\begin{array}{ll}\text { H2DCF-DA } & \text { 2'-7'-dihydro-dichlorofluorescein diacetate }^{\prime} \\ \text { MAPK } & \text { Mitogen-activated protein kinase } \\ \text { NADH } & \text { Nicotinamide adenine dinucleotide, reduced } \\ \text { NADPH } & \text { Nicotinamide adenine dinucleotide phosphate, reduced } \\ \text { NAD(P)H } & \text { NADH or NADPH } \\ \text { NBT } & \text { Nitroblue tetrazolium } \\ \text { NHBE } & \text { Normal human bronchial epithelial cell } \\ \text { QA } & \text { Quinacrine } \\ \text { ROS } & \text { Reactive oxygen species } \\ \text { RWE } & \text { Ragweed pollen extract } \\ \text { SPP } & \text { Subpollen particle }\end{array}$

\section{REFERENCES}

1. Grote M. In situ localization of pollen allergens by immunogold electron microscopy: allergens at unexpected sites. Int Arch Allergy Immunol. 1999; 118:1-6. [PubMed: 9925956]

2. Vrtala S, Grote M, Duchene M, van Ree R, Kraft D, Scheiner O, et al. Properties of tree and grass pollen allergens: reinvestigation of the linkage between solubility and allergenicity. Int Arch Allergy Immunol. 1993; 102:160-9. [PubMed: 8400895]

3. Suphioglu C, Singh MB, Taylor P, Bellomo R, Holmes P, Puy R, et al. Mechanism of grass-polleninduced asthma. Lancet. 1992; 339:569-72. [PubMed: 1347092]

4. Roberts G, Hurley C, Bush A, Lack G. Longitudinal study of grass pollen exposure, symptoms, and exhaled nitric oxide in childhood seasonal allergic asthma. Thorax. 2004; 59:752-6. [PubMed: 15333850]

5. Schappi GF, Taylor PE, Staff IA, Rolland JM, Suphioglu C. Immunologic significance of respirable atmospheric starch granules containing major birch allergen Bet v 1. Allergy. 1999; 54:478-83. [PubMed: 10380779]

6. Grote M, Vrtala S, Niederberger V, Valenta R, Reichelt R. Expulsion of allergen-containing materials from hydrated rye grass (Lolium perenne) pollen revealed by using immunogold field emission scanning and transmission electron microscopy. J Allergy Clin Immunol. 2000; 105:11405. [PubMed: 10856148]

7. Burge HA. An update on pollen and fungal spore aerobiology. J Allergy Clin Immunol. 2002; 110:544-52. [PubMed: 12373259]

8. Taylor PE, Flagan RC, Miguel AG, Valenta R, Glovsky MM. Birch pollen rupture and the release of aerosols of respirable allergens. Clin Exp Allergy. 2004; 34:1591-6. [PubMed: 15479275]

9. Barnes C, Schreiber K, Pacheco F, Landuyt J, Hu F, Portnoy J. Comparison of outdoor allergenic particles and allergen levels. Ann Allergy Asthma Immunol. 2000; 84:47-54. [PubMed: 10674565]

10. Wark PA, Simpson J, Hensley MJ, Gibson PG. Airway inflammation in thunderstorm asthma. Clin Exp Allergy. 2002; 32:1750-6. [PubMed: 12653167]

11. King TP. Chemical and biological properties of some atopic allergens. Adv Immunol. 1976; 23:77-105. [PubMed: 793359]

12. Rafnar T, Griffith IJ, Kuo MC, Bond JF, Rogers BL, Klapper DG. Cloning of Amb a I (antigen E), the major allergen family of short ragweed pollen. J Biol Chem. 1991; 266:1229-36. [PubMed: 1702434]

13. Menetrez MY, Foarde KK, Ensor DS. An analytical method for the measurement of nonviable bioaerosols. J Air Waste Manag Assoc. 2001; 51:1436-42. [PubMed: 11686248] 
14. Schappi GF, Suphioglu C, Taylor PE, Knox RB. Concentrations of the major birch tree allergen Bet $\mathrm{v} 1$ in pollen and respirable fine particles in the atmosphere. J Allergy Clin Immunol. 1997; 100:656-61. [PubMed: 9389296]

15. Grote M, Valenta R, Reichelt R. Abortive pollen germination: a mechanism of allergen release in birch, alder, and hazel revealed by immunogold electron microscopy. J Allergy Clin Immunol. 2003; 111:1017-23. [PubMed: 12743566]

16. Knox RB, Suphioglu C, Taylor P, Desai R, Watson HC, Peng JL, et al. Major grass pollen allergen Lol p 1 binds to diesel exhaust particles: implications for asthma and air pollution. Clin Exp Allergy. 1997; 27:246-51. [PubMed: 9088650]

17. Bacsi A, Dharajiya N, Choudhury BK, Sur S, Boldogh I. Effect of pollen-mediated oxidative stress on immediate hypersensitivity reactions and late-phase inflammation in allergic conjunctivitis. $\mathbf{J}$ Allergy Clin Immunol. 2005; 116:836-43. [PubMed: 16210058]

18. Boldogh I, Bacsi A, Choudhury BK, Dharajiya N, Alam R, Hazra TK, et al. ROS generated by pollen NADPH oxidase provide a signal that augments antigen-induced allergic airway inflammation. J Clin Invest. 2005; 115:1-13.

19. Day JP, Kell DB, Griffith GW. Differentiation of Phytophthora infestans sporangia from other airborne biological particles by flow cytometry. Appl Environ Microbiol. 2002; 68:37-45. [PubMed: 11772606]

20. Liochev SI, Fridovich I. Superoxide from glucose oxidase or from nitroblue tetrazolium? Arch Biochem Biophys. 1995; 318:408-10. [PubMed: 7733670]

21. Van Gestelen P, Asard H, Caubergs RJ. Solubilization and separation of a plant plasma membrane NADPH-O2- synthase from other NAD(P)H oxidoreductases. Plant Physiol. 1997; 115:543-50. [PubMed: 12223822]

22. Zhang S, Klessig DF. MAPK cascades in plant defense signaling. Trends Plant Sci. 2001; 6:520-7. [PubMed: 11701380]

23. Powell CS, Wright MM, Jackson RM. p38mapk and MEK1/2 inhibition contribute to cellular oxidant injury after hypoxia. Am J Physiol Lung Cell Mol Physiol. 2004; 286:L826-33. [PubMed: 14672918]

24. Das A, Hazra TK, Boldogh I, Mitra S, Bhakat KK. Induction of the human oxidized base-specific DNA glycosylase NEIL1 by reactive oxygen species. J Biol Chem. 2005; 280:35272-80. [PubMed: 16118226]

25. van Zandwijk N. N-acetylcysteine (NAC) and glutathione (GSH): antioxidant and chemopreventive properties, with special reference to lung cancer. J Cell Biochem Suppl. 1995; 22:24-32. [PubMed: 8538205]

26. Kawasaki T, Koita H, Nakatsubo T, Hasegawa K, Wakabayashi K, Takahashi H, et al. CinnamoylCoA reductase, a key enzyme in lignin biosynthesis, is an effector of small GTPase Rac in defense signaling in rice. Proc Natl Acad Sci U S A. 2006; 103:230-5. [PubMed: 16380417]

27. Liszkay A, Kenk B, Schopfer P. Evidence for the involvement of cell wall peroxidase in the generation of hydroxyl radicals mediating extension growth. Planta. 2003; 217:658-67. [PubMed: 12739149]

28. Edinger AL, Thompson CB. Death by design: apoptosis, necrosis and autophagy. Curr Opin Cell Biol. 2004; 16:663-9. [PubMed: 15530778]

29. Lam E, Kato N, Lawton M. Programmed cell death, mitochondria and the plant hypersensitive response. Nature. 2001; 411:848-53. [PubMed: 11459068]

30. Frahry G, Schopfer P. NADH-stimulated, cyanide-resistant superoxide production in maize coleoptiles analyzed with a tetrazolium-based assay. Planta. 2001; 212:175-83. [PubMed: 11216837]

31. Henricks PA, Nijkamp FP. Reactive oxygen species as mediators in asthma. Pulm Pharmacol Ther. 2001; 14:409-20. [PubMed: 11782121]

32. Rahman I. Oxidative stress, chromatin remodeling and gene transcription in inflammation and chronic lung diseases. J Biochem Mol Biol. 2003; 36:95-109. [PubMed: 12542980]

33. Thannickal VJ, Fanburg BL. Reactive oxygen species in cell signaling. Am J Physiol Lung Cell Mol Physiol. 2000; 279:L1005-28. [PubMed: 11076791] 
A
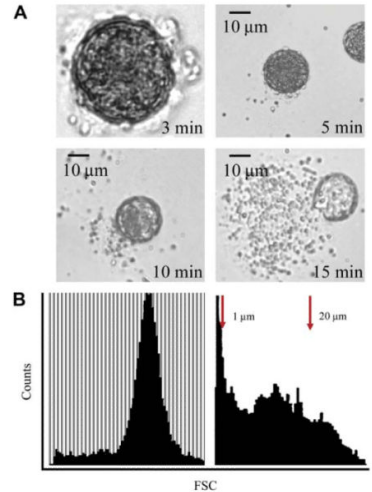

FIG 1.

Release of SPPs from ragweed pollen grains. A, Real-time microscopic images of SPPs release from ragweed pollen grains. Left to right, Vesicle-like formations on the pollen surface (magnification $\times 100$ ); the release of 0.5 to $4.5 \mu \mathrm{M}$ of SPPs $(5,10$, and 15 minutes). B, Size distributions of ragweed pollen grains 5 minutes (shaded panel) and 30 minutes (nonshaded panel) after hydration. FSC, Forward scatter parameter. 
A

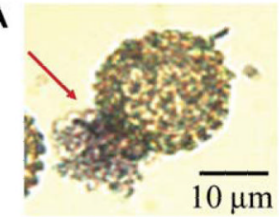

C

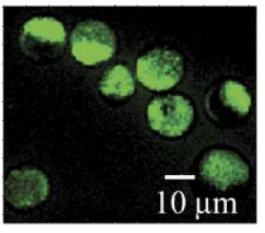

B
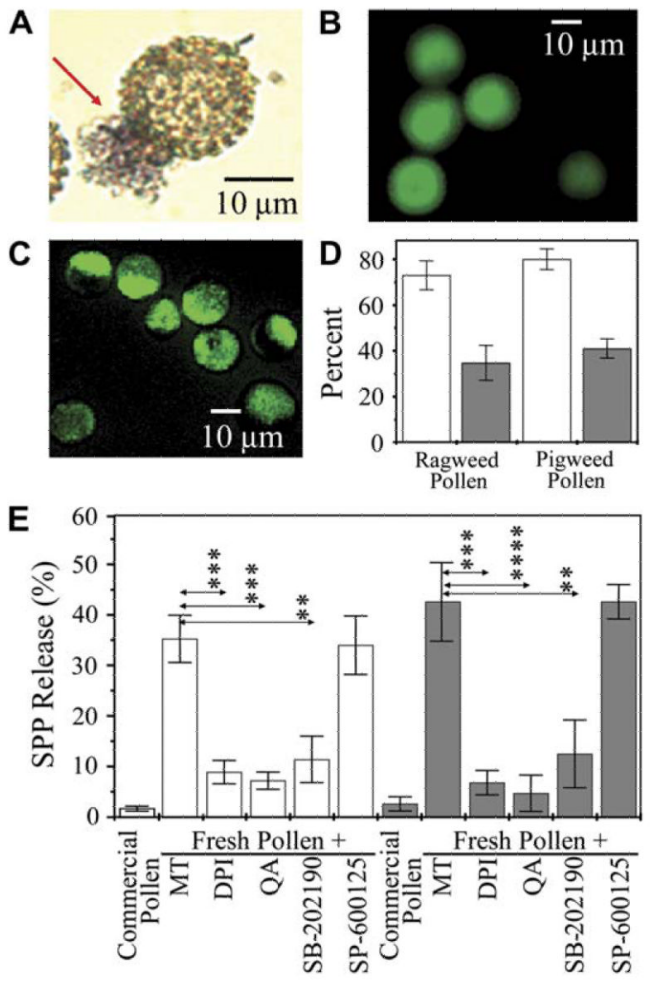

FIG 2.

Release of SPPs requires $\mathrm{NAD}(\mathrm{P}) \mathrm{H}$ oxidase activity. A, Formazan formation at the site of SPP release (ragweed pollen). $\mathbf{B}$ and $\mathbf{C}$, Ragweed (Fig 2, B) and pigweed (Fig 2, C) pollen grains oxidize $\mathrm{H}_{2}$ DCF-DA into fluorescent DCF. D, Percentage of the DCF-positive pollen particles (open columns) releasing SPPs (solid columns). E, Inhibition of SPP formation.

Open columns, Ragweed; solid columns, pigweed. All results are presented as means \pm SEM (n = 4-7). $* * P<.01 ; * * * P<.001 ; * * * * P<.0001$ versus control. $M T$, Mock treated. 

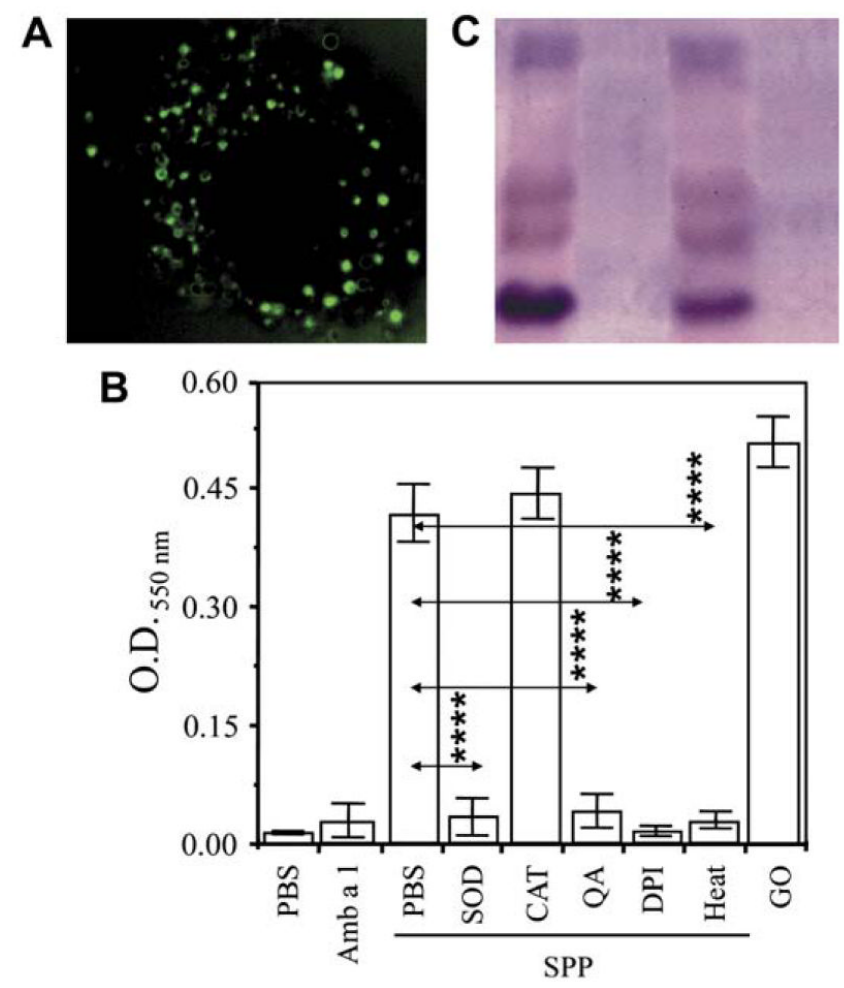

FIG 3.

SPPs possess redox activity. A, Ragweed SPPs showing DCF fluorescence (magnification $\times 196)$. B, SPP-mediated $\mathrm{O}_{2}{ }^{-}$generation is inhibited by $\mathrm{NAD}(\mathrm{P}) \mathrm{H}$ oxidase inhibitors or heat inactivation. $S O D$, Superoxide dismutase; $C A T$, catalase; $G O$, glucose oxidase. All results are presented as means \pm SEM $(\mathrm{n}=4-7)$. C, In-gel NBT reduction by proteins in SPPs after nondenaturing PAGE. Lane 1, SPP; lane 2, heat-treated SPP; lane 3, RWE; lane 4, heattreated RWE. $* * * * P<.0001$ versus control. 
A

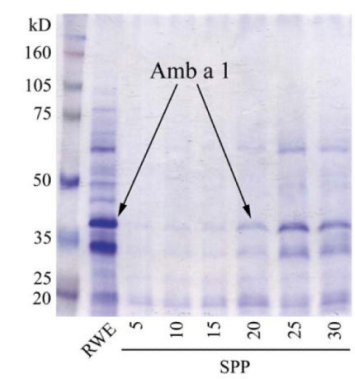

B

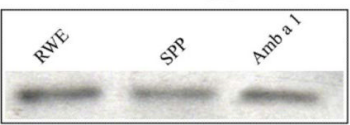

FIG 4.

SPPs from ragweed pollen grains contain Amb a 1. A, SDS-PAGE analysis of RWE and lysates of SPPs. The SPPs were released from the pollen grains and then lysed and subjected to SDS-PAGE. Fractionated proteins were stained with Coomassie brilliant blue G250. B, Amb a 1 in SPPs shown by means of Western blot analysis. 

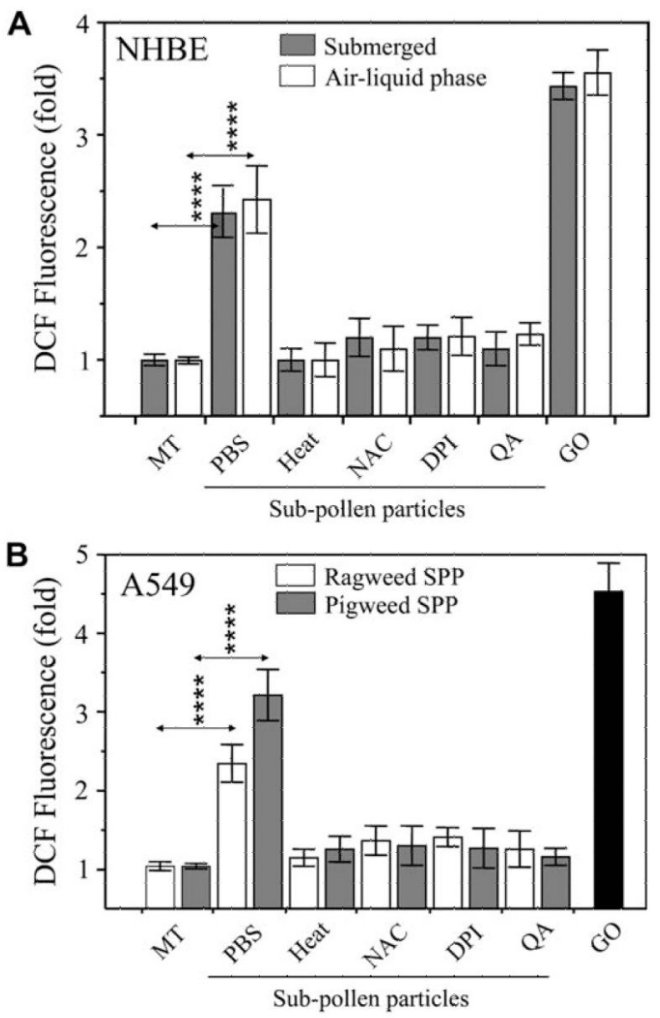

FIG 5.

SPPs increase levels of ROS in airway epithelial cells. A, NHBE cells grown in submerged (solid columns) or air-liquid interphase cultures (open columns) treated with ragweed SPP. B, A549 cells exposed to ragweed or pigweed SPPs. Glucose oxidase $(G O)$ was used as a positive control. $M T$, Mock treated; $N A C, \mathrm{~N}$-acetyl-L-cysteine. All results are presented as means \pm SEM of 4 to 6 measurements. $* * * * P<.0001$ versus control. 

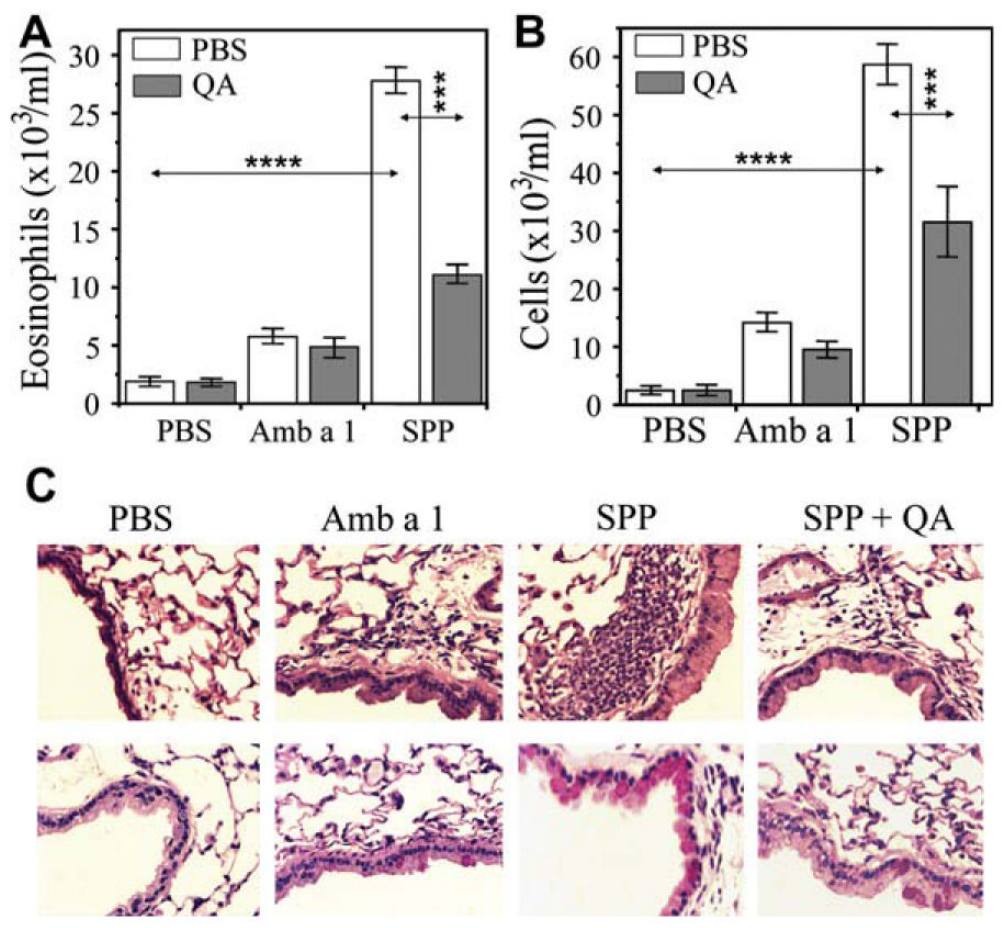

FIG 6.

$\mathbf{A}$ and $\mathbf{B}$, SPPs induce airway inflammation. Sensitized mice were challenged with PBS, Amb a 1, or SPPs with (solid columns) or without (open columns) QA. Eosinophils (Fig 6, $A$ ) and total inflammatory cells (Fig 6,B) in BAL fluids are shown ( \pm SEM; $\mathrm{n}=3-5)$. C, Inflammatory cell infiltration in the peribronchial area (upper row) and goblet cell metaplasia (lower row). Representative images of serial lung sections are shown $(n=7-9)$. $* * * P<.001 ; * * * * P<.0001$ versus control. 